\title{
A evolução recente da indústria farmacêutica brasileira nos limites da subordinação econômica
}

\author{
I ${ }^{1}$ Paulo Henrique Almeida Rodrigues, ${ }^{2}$ Roberta Dorneles Ferreira da Costa, \\ ${ }^{3}$ Catalina Kiss I
}

Resumo: Este artigo apresenta a evolução da indústria farmacêutica brasileira e da balança comercial entre 1996 e 2014 e discute possibilidades de mudanças na política industrial farmacêutica. Os pressupostos da pesquisa foram: que as possibilidades industriais para o setor estão fortemente conectadas com o cenário internacional; e que este piorou a partir dos anos 1990, tornando o país mais vulnerável. As fontes utilizadas foram a Pesquisa Industrial Anual, do Instituto Brasileiro de Geografia Estatística, e os dados da balança comercial do Sistema de Análise das Informaçôes, do Ministério da Indústria, Comércio Exterior e Serviços. Os valores foram deflacionados e corrigidos para desconsiderar a influência da inflação. Os resultados demonstraram que há um desequilíbrio entre a evolução das indústrias farmoquímica e de medicamentos para uso humano em relação à das indústrias voltadas para medicamentos veterinários e de produtos químicos para o agronegócio. A balança comercial mostrou-se crescentemente deficitária para produtos farmacêuticos para uso humano. Os resultados corroboraram tanto a hipótese de crescente subordinação econômica quanto os pressupostos do estudo acima apontados.

> Palavras-chave: indústria farmacêutica; indústria química; política industrial.

\author{
${ }^{1}$ Instituto de Medicina Social, \\ Universidade do Estado do Rio de \\ Janeiro. Rio de Janeiro-RJ, Brasil \\ (pharodrigues@gmail.com). \\ 0000-0002-3159-6711 \\ 2 Instituto de Medicina Social, \\ Universidade do Estado do Rio \\ de Janeiro. Rio de Janeiro-RJ, \\ Brasil (roberta_fdacosta@yahoo. \\ com.br). \\ 0000-0002-6370-9098
}

${ }^{3}$ Instituto de Medicina Social, Universidade do Estado do Rio de Janeiro. Rio de Janeiro-RJ, Brasil (catalinakiss9@gmail.com). 0000-0001-6298-8681
Recebido em: 13/07/2017 Aprovado em: 17/10/2107 Revisado em: 21/02/2018 


\section{Introdução}

Desde o reconhecimento do direito universal à saúde no Brasil, em 1988, o acesso da população aos medicamentos se tornou uma questão-chave para a viabilidade e a sustentabilidade do Sistema Único de Saúde (SUS). Nesse período, entretanto, a indústria farmacêutica no Brasil passou a contar com condições difíceis para seu desenvolvimento por conta de mudanças na política econômica, que abandonou medidas protecionistas que a favoreciam. Tais condiçóes difíceis contrastam com o fato de o país ser reconhecido como um dos 13 em todo o mundo que têm uma indústria capaz de fabricar tanto insumos farmacêuticos ativos (IFAs), quanto medicamentos acabados e de que seu mercado interno figura entre os dez maiores do mundo (WHO, 2004, p. 6 e 33). O setor farmacêutico brasileiro é cada vez mais dependente de importaçôes (MAGALHÃES, 2003; GADELHA, 2003; ABDI, 2013) e apresenta crescente déficit comercial, o sexto maior do mundo no setor (PINTO; BARREIRO, 2013, p. 1.558). A produção interna de IFAs é ínfima e decrescente, fazendo com que $90 \%$ das necessidades do setor sejam supridas atualmente por importações, segundo dados da Associação Brasileira da Indústria Farmoquímica e de Insumos Farmacêuticos - ABIQUIFI (MITIDIERI et al., 2015, p. 2).

Por conta dessa crescente dependência de importaçôes, o país chegou a uma situação de grave vulnerabilidade sanitária, ao ponto de gerar uma situação de desabastecimento de medicamentos (REZENDE, 2016), a exemplo do caso da penicilina para o tratamento de uma doença importante como a sífilis congênita, que foi objeto de alerta do Ministério da Saúde (BRASIL, 2016) e chegou a ser noticiado pela grande mídia (GLOBO.COM, 22/7/2016; MAGALHÁES, 2003) e levou o debate ao Senado brasileiro (SENADO FEDERAL, 12/7/2017). A ausência de plantas farmoquímicas para a produção de antibióticos por fermentação torna o país inteiramente refém das importações e fortemente dependente em um setor importante para a saúde da populaçấo (COSTA et al., 2014). Os gastos com medicamentos realizados pelo Ministério da Saúde e pelas Secretarias de Saúde vêm aumentando de forma preocupante; entre 2010 e 2015, esse crescimento foi da ordem de 40\% (BRASIL, 2011; VIEIRA, 2017, p. 129). Todos esses fatores vêm contribuindo para reduzir a capacidade de o SUS assegurar o acesso dos seus usuários aos medicamentos. 
Cabe ressaltar que a produção de medicamentos ocupa um lugar central no processo de acumulaçáo de capital internacional, sendo um dos ramos industriais mais lucrativos (SCHWEITZER, 2007). O setor é historicamente oligopolizado e tem seu núcleo localizado em poucos países centrais do sistema interestatal capitalista, conceito utilizado por José Luís Fiori (2014) para explicar a relação hierárquica existente entre os diferentes Estados que o compóem. As grandes indústrias farmacêuticas mundiais têm sede em poucos países - Estados Unidos, Alemanha, Suíça, França e Reino Unido -, onde ocorrem os principais processos de investimento em pesquisa e desenvolvimento $(\mathrm{P} \& \mathrm{D})$, que são de importância vital para o setor (ACHILLADELIS; ANTONAKIS, 2001). Pode-se acrescentar que, como as sedes das empresas e o processo de pesquisa e inovação tecnológica estão localizados nesses poucos países, os resultados do processo de acumulação de capital no setor também estáo concentrados nos mesmos.

O primeiro pressuposto que orienta este estudo parte da possibilidade de que as políticas para produção de medicamento e farmoquímico no Brasil estão fortemente conectadas tanto com a conjuntura internacional, quanto com os desdobramentos das decisóes políticas internas tomadas por diferentes governos nos últimos 25 anos. A retirada da proteção externa à indústria farmacêutica e a mudança na política de patentes, nos governos Collor de Mello e Fernando Henrique Cardoso, criaram condiçôes desfavoráveis para a produção local de fármacos e medicamentos (KORNIS et al., 2008, p. 92; DÓRIA et al., 2016, p. 32).

Depois dessas medidas, só foram tomados três caminhos, que buscaram fomentar a política industrial do Estado brasileiro: engenharia reversa restrita aos antirretrovirais, genéricos e as parcerias de desenvolvimento produtivo (PDPs). Isso ocorreu mesmo depois de 2003, quando a Política Industrial e de Ciência e Tecnologia (PICTE) selecionou o setor como um dos quatro prioritários em função do déficit comercial do setor e da necessidade de fortalecimento da produção de fármacos e medicamentos constantes na Relaçáo Nacional de Medicamentos Essenciais (Rename), tendo em vista o vínculo deste setor com as políticas sanitárias. O primeiro daqueles caminhos visou ao enfrentamento com a indústria farmacêutica internacional em relação à produção local de dois antirretrovirais - Nelfinavir, da Roche ${ }^{\bullet}$ e Efavirenz, da Merck $^{\oplus}$ - por engenharia reversa, a partir de 1998. $\mathrm{O}$ investimento realizado no Instituto Tecnológico em Fármacos (Farmanguinhos) 
da Fundação Oswaldo Cruz aumentou o poder de barganha do governo brasileiro na negociaçáo com os laboratórios multinacionais que detinham as patentes de antirretrovirais (LOYOLA, 2010, p. 19).

O segundo caminho mencionado, produção interna de genéricos, a partir de 1999, também tinha relação com a questão dos antirretrovirais (LOYOLA, 2010, p. 19) e visava, sobretudo, ampliar a oferta e baixar os gastos públicos e da sociedade, em geral, com medicamentos. O último dos caminhos mencionados, as PDPs, resultou da PITCE de 2003 e visou à transferência de tecnologia para a ampliação da produção de medicamentos considerados estratégicos para o SUS, bem como articular medidas que estabelecessem uma redução dos preços praticados desse medicamento para aquisição do governo federal (GADELHA et al, 2013).

O segundo pressuposto deste artigo é o de que, ao aceitar as regras do jogo internacional, a dinâmica produtiva da economia brasileira vem se desenvolvendo, desde 1990, em torno das atividades primárias, como o agronegócio e a mineração. Tal situação teve origem nas pressóes em torno da crise da dívida externa, que serviram de base para a gradual imposição ao país do que Reinaldo Gonçalves (2013) chama de 'modelo liberal periférico' (MLP) e Brasilio Sallum Jr. (2008), de 'hegemonia liberal'. Como a caracterização dada por ambos da situação é muito semelhante, adotamos neste artigo a primeira denominação.

Tal modelo veio substituir o modelo desenvolvimentista, que prevaleceu entre 1930 e 1980. O MLP tem como principais características: liberalização, privatização e desregulação, desindustrialização, aumento das importaçóes, reprimarização das exportaçôes (especialização regressiva), dependência tecnológica, desnacionalização e vulnerabilidade externa estrutural, além da dominação do capital financeiro (CARCANHOLO, 2010; CANO, 2012; GONÇALVES, 2013; GIOMO; BARCELOS, 2016). Um conceito-chave do mesmo foi o de "inserção competitiva”, ideia reformista de cunho liberal que começou a se desenvolver a partir de 1983, em plena crise da dívida externa (SALLUM JR., 2015, p. 48-53). Mais tarde ela seria defendida pelo Partido da Social Democracia Brasileira (PSDB) nos governos Fernando Henrique Cardoso, tendo sido renomeada, a partir de 2004, pelo Governo Lula como 'inserção econômica competitiva'. Dos dois pressupostos que orientaram a pesquisa, derivou a hipótese da mesma, de que a consolidação do MLP condicionou a evolução da IFB e do setor industrial químico como um 
todo, favorecendo principalmente os subsetores associados à produção de produtos primários para a exportação, como é apresentado mais adiante.

Uma vez que o MLP implica a reprimarização das exportaçóes, consideramos importante verificar os dados sobre a IFB em comparação com as classes do ramo industrial químico ligadas ao agronegócio, que são: defensivos agrícolas; adubos e fertilizantes; e medicamentos para uso veterinário, assim como para o setor químico como um todo. Desta forma, o presente artigo apresenta os resultados de levantamento sobre a evolução da indústria farmacêutica brasileira entre 1996 e 2014, com o intuito principal de explorar o comportamento recente desse setor táo importante para a sustentabilidade do SUS. Também foram analisados dados da balança comercial do setor, para verificar o grau de dependência das importaçóes; e com isso elaborar um dimensionamento ante a vulnerabilidade econômica e sanitária do país e resgatar a discussão sobre o tema feita por outros autores (MAGALHÃES et al., 2003; GADELHA, 2003, 2006, 2008/2009).

\section{Métodos}

Com base nos dois pressupostos apresentados acima, o estudo exploratório buscou verificar se o modelo econômico iniciado nos anos 1990, que enfatizou a reprimarização da economia, influenciou a dinâmica da indústria farmacêutica no Brasil e, consequentemente, sua capacidade de atender às necessidades de abastecimento de medicamentos do SUS e da população em geral. Nesse sentido, o primeiro procedimento da pesquisa visou levantar os dados relativos à evolução da produção industrial do setor. A principal fonte de dados existente para tanto é a Pesquisa Industrial Anual (PIA), desenvolvida anualmente pelo Instituto Brasileiro de Geografia Estatística (IBGE). Para o estudo, foram selecionados dados relativos ao grupo de "fabricação de produtos químicos", e dentro deste: as classes de "fabricação de produtos farmacêuticos e farmoquímicos"; "fabricação de defensivos agrícolas" (agrotóxicos); e "fabricação de medicamentos para uso veterinário". A escolha dessas últimas classes de indústria se justificou em função da dinâmica da economia ter se centrado na produção de produtos primários de exportação, supondo-se que a demanda de produtos para o agronegócio poderia favorecer mais o aumento da produção nessas classes de indústria do que nas de produção de medicamentos para uso humano e mesmo de farmoquímicos. A organização desses dados permitiu 
a realização de uma análise comparativa entre o grupo e as classes de indústrias selecionadas. Outros estudos com base na PIA/IBGE também buscaram a relação entre o modelo econômico atual e a reprimarização da economia, ou a especialização produtiva, como foi o caso Danielle Giomo e Marina Assunção Barcelos (2016), que afirmam estar ocorrendo um processo de concentração da nossa indústria em produtos de baixo valor tecnológico.

Os dados foram retirados das tabelas completas da PIA, relativas às empresas. Como a PIA teve início em 1996, tendo por base a Classificação Nacional de Atividades Econômicas - CNAE (IBGE, 2004, p. 13), foram levantados os dados relativos a cada ano do período compreendido entre 1996 e 2014. Cabe destacar que o período adotado, embora náo cubra todo o tempo do MLP, iniciado em 1990, abrange a maior parte do mesmo, o que inclui desde a segunda metade do primeiro mandato do governo Fernando Henrique Cardoso até o final do primeiro mandato do governo Dilma Rousseff. É necessário dizer que no ano de 2008 houve uma mudança na CNAE, até então o IBGE utilizava a CNAE 1.0, passando a adotar a versão 2.0. Até 2007, as empresas fabricantes de produtos farmoquímicos eram enquadradas como parte dos fabricantes de produtos farmacêuticos e não havia a classe "fabricação de preparaçôes farmacêuticas". Para tratar os dados, tivemos de fazer um ajuste entre as duas formas de classificação, que implicou os seguintes procedimentos: a) Retirada dos fabricantes de produtos farmoquímicos dos fabricantes de produtos farmacêuticos, entre 2000 e 2007; b) criação de um subtotal "fabricantes de produtos farmoquímicos e farmacêuticos" para o período 2000 a 2007; e c) não consideração em separado dos dados relativos aos fabricantes de preparaçôes farmacêuticas em todo o período (2000 a 2012). Na primeira versão, a indústria química correspondia à divisão "Fabricação de produtos químicos", com o código 24, enquanto as empresas de "Fabricação de produtos farmacêuticos" eram um grupo com o código 24.5 (ver Quadro 1, a seguir). 
Quadro 1. IBGE, PIA, Divisão, grupos e classes de atividade, CNAE 1.0 e 2.0

\begin{tabular}{|c|l|l|}
\hline Divisão, grupos e classes de atividades & CNAE 1.0 (1996 a 2007) & CNAE 2.0 (2008...) \\
\hline Produtos químicos & 24 & 20 \\
\hline Adubos e fertilizantes & 24.13 & $20.13-4$ \\
\hline Defensores agrícolas & 24.6 & $20.51-7$ \\
\hline Produtos Farmoquímicos e Farmacêuticos & NA & 21 \\
\hline Produtos Farmoquímicos & $24.51-1$ & $21.10-6$ \\
\hline Produtos Farmacêuticos & 24.5 & 21.2 \\
\hline Medicamento para uso veterinário & $24.53-8$ & $21.22-0$ \\
\hline Medicamento para uso humano & $24.52-0$ & $21.21-1$ \\
\hline
\end{tabular}

Fontes: IBGE, 2004 e 2007.

Para as categorias selecionadas, foram observadas as seguintes variáveis consideradas significativas para os objetivos da pesquisa: número de empresas (tabela 101 da PIA/IBGE); pessoal ocupado total (tabela 101); receita bruta total (tabela 102); receita líquida de vendas - RLV (tabela 102); receita total (tabela 102); e o valor da transformação industrial - VTI (tabela 104). Convém mencionar que o VTI corresponde à diferença entre o valor bruto da produção industrial menos os custos das operaçóes industriais e constitui um proxy para o lucro. Com vistas a permitir uma aproximaçáo com a questão da concentração/desconcentração industrial, resolvemos acrescentar, ainda, a variável média de pessoal ocupado, que corresponde à divisão do pessoal ocupado total pelo número de empresas. Visando à comparabilidade entre os valores financeiros - receita bruta total, RLV e VTI trabalhados pela pesquisa, estes foram corrigidos para o ano de 2014 , com base na variação anual do IPCA calculada pelo IBGE, obtidos junto ao bando de dados IPEADATA do Instituto de Pesquisa Econômica Aplicada (IPEA, 27/11/2016).

$\mathrm{O}$ segundo procedimento de pesquisa envolveu o levantamento e a análise dos dados da balança comercial relativa aos medicamentos no período considerado, visando verificar se a opção pela reprimarização da economia teria afetado negativamente a balança, como a literatura aponta (MAGALHÁES et al., 2003; GADELHA, 2003), gerando crescente déficit comercial no setor. A confirmação dessa tendência contribuiria para a vulnerabilidade e dependência do país no setor farmacêutico, na medida em que a ampliação da dependência de 
importaçóes pode afetar a capacidade de abastecimento de medicamentos no país. Para verificar a evolução da balança comercial do setor, foi utilizado o Sistema de Análise das Informaçôes de Comércio Exterior, denominado AliceWeb2, da Secretaria de Comércio Exterior, do Ministério da Indústria, Comércio Exterior e Serviços (MDIC). A partir das informaçôes da balança comercial, foram extraídos e analisados os dados relativos às importação e exportaçáo de medicamentos acabados e náo prontos para a venda, no período de 1996 a 2014. Tais dados estão disponíveis em dólar (US\$), Free on Board (FOB), os quais foram corrigidos para dezembro de 2014, de acordo com a variação anual do Índice de Preços ao Consumidor (IPC) dos Estados Unidos (TRIAMI; HOMEFINANCE, 27/11/2016).

\section{Resultados e Discussão}

\section{A evoluçáo desigual dos setores selecionados}

A pesquisa levantou os dados ano a ano, tanto para a indústria, quanto para a balança comercial, mas como o espaço de um artigo náo permite apresentar e discutir em detalhe o conjunto dos dados, optou-se por mostrar e discutir a evolução percentual das variáveis selecionadas relativas aos setores (classe e classes na nomenclatura da PIA/IBGE), de 1996 a 2014 (Tabela 1 e Gráfico 1, a seguir).

Tabela 1. Evoluçáo (\%) dos indicadores selecionados para as classes de empresas de fabricação de: defensivos agrícolas, adubos e fertilizantes, medicamentos para uso veterinário e para uso humano, produtos farmoquímicos e a divisão de produtos químicos, 1996-2014

\begin{tabular}{|c|c|c|c|c|c|c|c|}
\hline Ano & $\begin{array}{c}\text { Defensivos } \\
\text { agrícolas } \\
(20.51-7)\end{array}$ & $\begin{array}{c}\text { Adubos e } \\
\text { fertilizantes } \\
(20.13-4)\end{array}$ & $\begin{array}{l}\text { Medicamentos } \\
\text { para uso } \\
\text { veterin. } \\
(21.22-0)\end{array}$ & $\begin{array}{c}\text { Medicamentos } \\
\text { para uso } \\
\text { humano } \\
(21.21-1)\end{array}$ & $\begin{array}{c}\text { Produtos } \\
\text { farmacêuticos } \\
\text { (21.2) }\end{array}$ & $\begin{array}{c}\text { Produtos } \\
\text { farmoquí- } \\
\text { micos } \\
(21.10-6)\end{array}$ & $\begin{array}{c}\text { Produtos } \\
\text { químicos (20) }\end{array}$ \\
\hline N. de empresas & $-5,6$ & 90,5 & 106,7 & $-13,4$ & $-11,7$ & $-43,8$ & 23,1 \\
\hline Pessoal ocupado total & 152,4 & 123,9 & 112,3 & 85,4 & 92,2 & $-45,9$ & 7,4 \\
\hline $\begin{array}{l}\text { Média de pessoal } \\
\text { ocupado por empresa }\end{array}$ & 167,2 & 17,5 & 2,7 & 114,0 & 117,6 & $-3,7$ & $-12,8$ \\
\hline $\begin{array}{l}\text { Receita líquida de } \\
\text { vendas }\end{array}$ & 1149,3 & 1059,4 & 613,4 & 523,3 & 490,4 & 98,5 & 461,8 \\
\hline $\begin{array}{l}\text { Valor da transformação } \\
\text { industrial }\end{array}$ & 696,9 & 686,9 & 402,5 & 322,4 & 334,1 & 79,9 & 137,7 \\
\hline
\end{tabular}

Fonte: elaboração própria, com base em: IBGE, Pesquisa Industrial Anual - Empresa, PIA-Empresa, 1996 a 2014, dados financeiros corrigidos pelo IPCA de 12/2014. 
Gráfico 1. Evolução (\%) dos indicadores selecionados para as classes de empresas de fabricação de: defensivos agrícolas, adubos e fertilizantes, medicamentos para uso veterinário e para uso humano, produtos farmoquímicos e a divisão de produtos químicos, 1996-2014

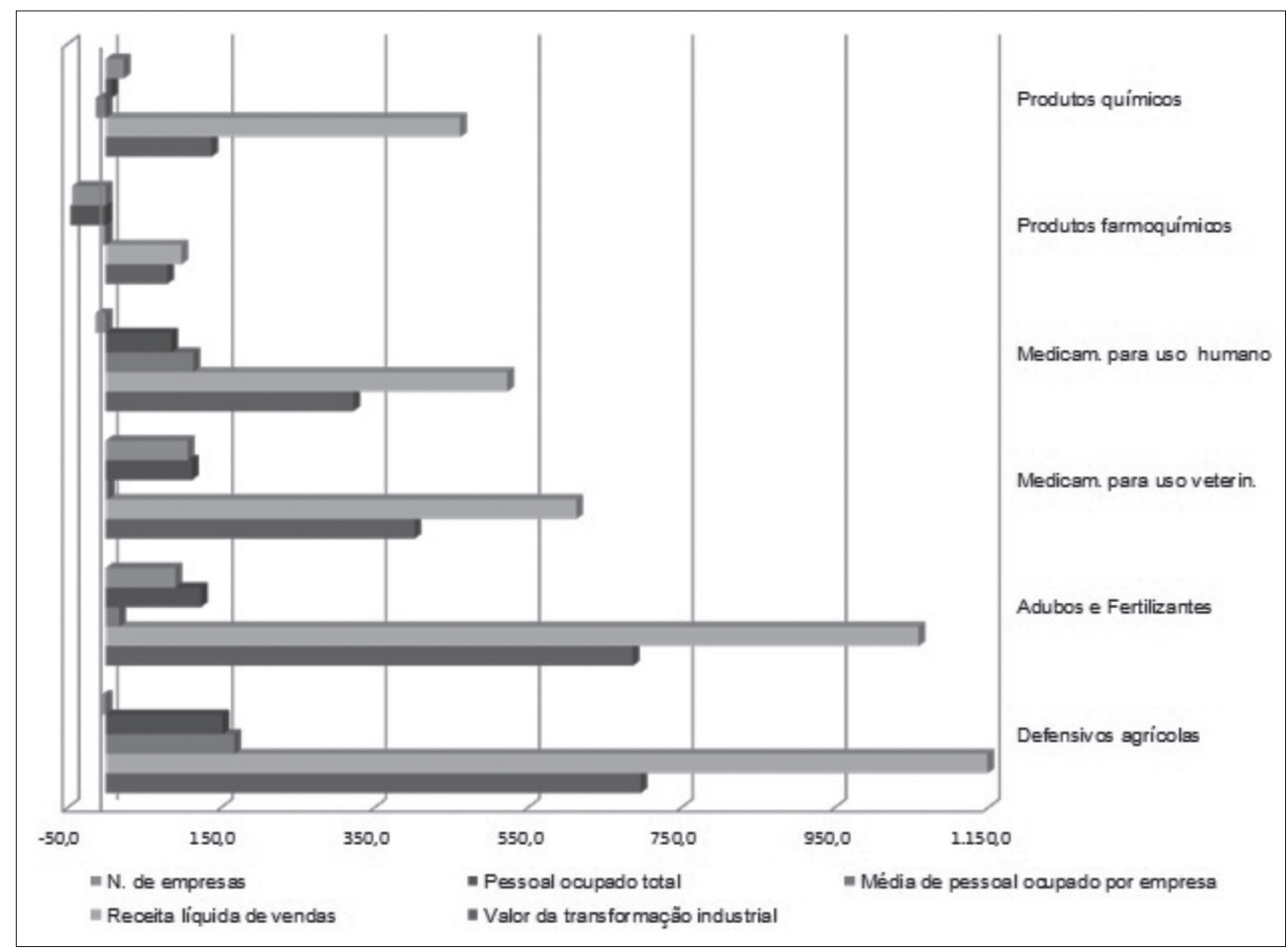

Fonte: elaboração própria, com base em: IBGE, Pesquisa Industrial Anual - Empresa, PIA-Empresa, 1996 a 2014, dados financeiros corrigidos pelo IPCA de 12/ 2014.

Os dados da tabela 1 e do gráfico 1 mostram que enquanto houve no período um aumento do número de empresas de fabricação de produtos químicos como um todo $(23,1 \%)$, ocorreu também queda do número de empresas nas classes de defensivos agrícolas $(-5,6 \%)$, medicamentos para uso humano $(13,4 \%)$, de produtos farmoquímicos $(-43,8 \%)$, no grupo de produtos farmacêuticos $(-11,7 \%)$, o que sugere a ocorrência de concentração industrial nesses setores. Tal possível concentração encontra correspondência no movimento internacional das indústrias farmoquímica e farmacêutica (VARGAS et al., 2014; MITIDIERI et al., 2015).

As variáveis relativas ao pessoal ocupado total e média por empresa, que também podem indicar sobre a concentração ou a desconcentração industrial, apresentaram comportamento positivo para todos os setores, exceto para farmoquímicos - com 
quedas de 45,9\% no pessoal ocupado total e de 3,7\% na média de pessoal ocupado por empresa. Quanto à classe de empresas de medicamentos para uso humano, quando se compara a queda no número de empresas, já comentada, com o aumento de $85,4 \%$ no pessoal ocupado total e de $114 \%$ na média de pessoal ocupado por empresa, fica mais evidente a possibilidade de estar ocorrendo uma concentração industrial neste setor. Já as quedas verificadas no setor farmoquímico, tanto no número de empresas, quanto de pessoal ocupado, sugerem que mais do que a ocorrência de concentração, teria havido uma desindustrialização no setor.

Quando se analisa a evoluçáo dos dados sobre a receita líquida de vendas (RLV) e o valor da transformaçáo industrial (VTI), fica claro que o maior crescimento ocorreu entre as empresas de fabricação de: defensivos agrícolas (RLV: 1.149,3\%; VTI: 696,9\%); adubos e fertilizantes (RLV: 1.059,4\%; VTI: 686,9\%); e medicamentos para uso veterinário (RLV: 613,4\%; VTI: 402,5\%). Depois dessas, a classe que apresentou crescimento relativo considerável foi a de medicamentos para uso humano (RLV: 523,3\%; VTI: 322,4\%). Já a classe de menor crescimento foi a de produtos farmoquímicos (RLV: 98,5\%; VTI: 79,9\%). Tais resultados são coerentes com a hipótese da pesquisa, uma vez que o maior crescimento ocorreu nas classes associadas ao perfil de uma economia centrada na produção de commodities - defensivos agrícolas, adubos e fertilizantes e medicamentos para uso veterinário -, enquanto o menor crescimento se deu na classe de produtos farmoquímicos, que é a base para a indústria farmacêutica como um todo e é classificada no Brasil como indústria de média-alta intensidade tecnológica (IBGE, 2010 p. 39). Esses resultados confirmam a hipótese da reprimarização da economia levantada por diversos autores (CARCANHOLO, 2010; CANO, 2012; GONÇALVES, 2013; PINTO; GONÇALVES, 2016; GIOMO; BARCELOS, 2016).

\section{Desequilíbrio do setor farmoquímico em relação ao de medicamentos}

A tabela 2 e o gráfico 2, a seguir, relacionam a receita líquida de vendas (RLV) das empresas de produçáo de farmoquímicos com as de medicamentos. Os dados evidenciam a crescente disparidade entre a capacidade produtiva das primeiras em relação às segundas, além de indicarem que o país vem ficando crescentemente dependente da importação de farmoquímicos. Magalhães et al. (2003, p. 44-45) já apontavam a tendência ao crescimento explosivo das importaçôes e do déficit da 
balança comercial de farmoquímicos, o qual havia passado de US $\$ 750$ milhóes para US\$1,8 bilhão, de 1990 para 2000, após o fim das medidas protecionistas no governo Collor de Mello. Esta situação vem se agravando, tendo o déficit atingido US\$ 2,4 bilhōes em 2011 (COSTA et al., 2014, p. 445).

Tabela 2. Relação entre a RLV da classe de empresas de fabricação de produtos farmoquímicos com as de medicamentos para uso veterinário e medicamentos para uso humano, 1996-2014 (R\$1.000,00)

\begin{tabular}{|r|r|r|r|r|r|}
\hline Ano & $\begin{array}{c}\text { Medicam. } \\
\text { para uso } \\
\text { veterin. }\end{array}$ & $\begin{array}{c}\text { Medicam. } \\
\text { para uso } \\
\text { humano }\end{array}$ & $\begin{array}{l}\text { Total de } \\
\text { medica- } \\
\text { mentos }\end{array}$ & $\begin{array}{c}\text { Produtos } \\
\text { farmo- } \\
\text { químicos }\end{array}$ & $\begin{array}{c}\text { Relação (\%) } \\
\text { Farmoq. I } \\
\text { total de } \\
\text { Medicam. }\end{array}$ \\
\hline 1996 & 534.073 & 7.407 .333 & 7.941 .406 & 217.988 & 2,74 \\
\hline 1998 & 717.890 & 9.569 .124 & 10.287 .014 & 240.636 & 2,34 \\
\hline 2000 & 1.071 .681 & 11.284 .044 & 12.355 .725 & 395.628 & 3,20 \\
\hline 2002 & 1.024 .266 & 15.461 .702 & 16.485 .968 & 166.327 & 1,01 \\
\hline 2004 & 1.049 .022 & 20.050 .766 & 21.099 .788 & 369.596 & 1,75 \\
\hline 2006 & 1.435 .024 & 23.200 .055 & 24.635 .079 & 193.419 & 0,79 \\
\hline 2008 & 1.765 .428 & 27.059 .702 & 28.825 .130 & 305.124 & 1,06 \\
\hline 2010 & 2.428 .028 & 34.097 .662 & 36.525 .690 & 434.799 & 1,19 \\
\hline 2012 & 2.947 .130 & 37.436 .939 & 40.384 .069 & 489.943 & 1,21 \\
\hline 2014 & 4.054 .267 & 49.128 .331 & 53.182 .598 & 460.514 & 0,87 \\
\hline Média & 1.688 .066 & 22.973 .320 & 24.661 .386 & 304.724 & 1,44 \\
\hline
\end{tabular}

Fonte: elaboração própria, com base em: IBGE, Pesquisa Industrial Anual - Empresa, PIA-Empresa, 1996 a 2014, dados financeiros corrigidos pelo IPCA de dezembro de 2014.

Os dados da tabela mostram como é ínfima a relação entre a RLV da classe de empresas de fabricação de farmoquímicos em comparação com as classes de medicamentos para uso veterinário e humano, especialmente em relação à última, representando em média apenas $1,44 \%$ daquelas. No período estudado, a relação caiu de $2,74 \%$ para $0,87 \%$, o que equivale a uma queda de $68,45 \%$. Cabe ressaltar que a relação atingiu seu ponto mínimo em 2006, quando representou apenas $0,79 \%$ da produção de medicamentos. Além da tendência de queda, a grande variação do peso relativo do setor ano a ano, como revelam os dados da tabela 2 e o gráfico 2, mostra que o setor pode ser mais sensível às variaçóes cambiais, aspecto que não foi considerado neste estudo. 
Gráfico 2. Relaçáo entre a RLV da classe de empresas de fabricaçáo de produtos farmoquímicos com as de medicamentos para uso veterinário e medicamentos para uso humano, 1996-2014 (R $1.000,00)$

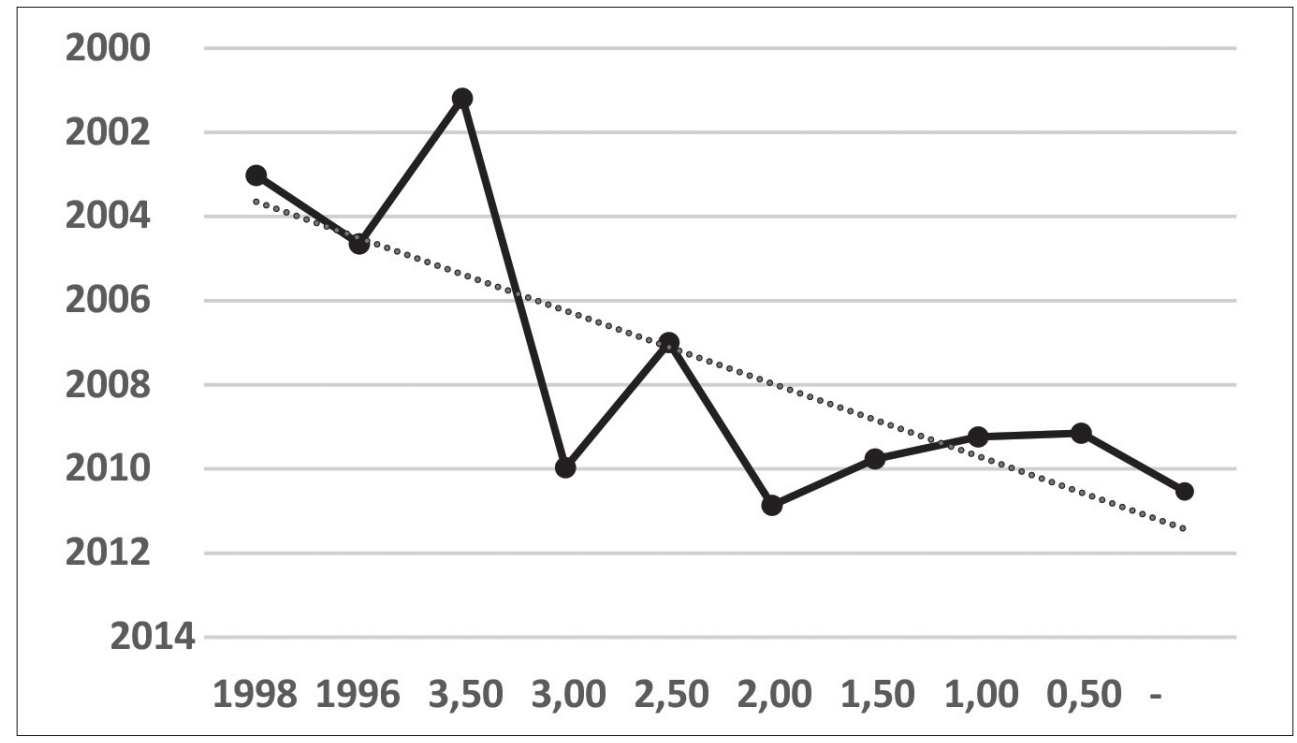

Fonte: elaboração própria, com base em: IBGE, Pesquisa Industrial Anual - Empresa, PIA-Empresa, 1996 a 2014, dados financeiros corrigidos pelo IPCA de dezembro de 2014.

$\mathrm{O}$ fato de a indústria farmoquímica representar uma proporção táo pequena da indústria de medicamentos e em queda indica, em primeiro lugar, a crescente vulnerabilidade do parque produtivo do país, tanto do ponto de vista sanitário, quanto econômico. Do ponto de vista sanitário, porque o país depende da importação de mais de $90 \%$ em média dos IFAs, que já vem trazendo problemas graves, como o do desabastecimento de medicamentos considerados essenciais. O estudo de Jorge Carlos Santos da Costa et al. mostra um quadro grave da situação desse subsetor: "a produção de IFAs representa apenas $0,8 \%$ da quantidade importada" (2014, p. 457). Do ponto de vista econômico, pelo grande e crescente déficit na balança comercial, também já apontado. Tais fatos também são coerentes com o modelo liberal periférico, confirmando a hipótese da pesquisa. Além disso, pode-se dizer que a tendência de redução da capacidade produtiva do país em relação aos IFAs revela o crescente gap tecnológico no setor entre o Brasil e o centro do sistema interestatal capitalista, o que é observado por autores e estudos (NEPP, 2000; SENNES, 2008; BRASIL, 2011; COSTA et al., 2014). 


\section{O déficit crescente na balança de medicamentos}

Diversos autores mostram a grande e crescente dependência brasileira das importaçóes e o consequente déficit comercial resultante de produtos químicos em geral (BASTOS; COSTA, 2011) e de farmoquímicos e produtos farmacêuticos em geral (MAGALHÃES et al., 2003; GADELHA, 2006, 2008/2009; VARGAS et al., 2010; ABDI, 2013; GOMES et al., 2014). Em função das evidências apresentadas pela literatura e os argumentos anteriores expostos neste artigo, é conveniente apresentar e analisar, neste ponto, o comportamento da balança comercial no período estudado. Procurou-se verificar os dados relativos às exportaçóes e importaçóes de medicamentos acabados, obtidos do Sistema ALICEweb2, do Ministério de Indústria, Comércio Exterior e Serviços. A tabela 3 e o gráfico 3, abaixo, mostram os saldos para medicamentos acabados - não prontos e prontos para a venda comparados com o saldo total da balança comercial brasileira.

Tabela 3. Evoluçáo dos saldos da balança comercial relativos aos medicamentos acabados não prontos e medicamentos acabados prontos para a venda, 1996-2014 (em US\$ milhóes, FOB)

\begin{tabular}{|c|c|c|c|}
\hline Ano & $\begin{array}{c}\text { A } \\
\text { Saldo BC - } \\
\text { Medicamentos } \\
\text { acabado (nāo } \\
\text { pronto para } \\
\text { venda) }\end{array}$ & $\begin{array}{c}\text { B } \\
\text { Saldo BC- } \\
\text { Medicamentos } \\
\text { acabado (pronto } \\
\text { para venda) }\end{array}$ & $\begin{array}{l}\text { Medicamentos } \\
\text { acabados (A+B) }\end{array}$ \\
\hline 1996 & $-79,16$ & $-449,69$ & $-528,85$ \\
\hline 1998 & $-92,84$ & $-710,23$ & $-803,08$ \\
\hline 2000 & $-87,82$ & $-776,41$ & $-864,23$ \\
\hline 2002 & $-99,24$ & $-757,81$ & $-857,05$ \\
\hline 2004 & $-134,67$ & $-836,24$ & $-970,91$ \\
\hline 2006 & $-79,10$ & $-1.291,28$ & $-1.370,37$ \\
\hline 2008 & $-72,90$ & $-2.007,74$ & $-2.080,64$ \\
\hline 2010 & $-87,95$ & $-2.264,27$ & $-2.352,22$ \\
\hline 2012 & $-83,86$ & $-2.502,29$ & $-2.586,15$ \\
\hline 2014 & $-105,43$ & $-2.477,14$ & $-2.582,57$ \\
\hline $\begin{array}{l}2014 / \\
1996(\%)\end{array}$ & 133,19 & 550,86 & 488,34 \\
\hline$\%$ & 5,8 & 94,2 & 100,0 \\
\hline
\end{tabular}

Fonte: elaboração própria com base em dados do Sistema de Análise das Informaçôes de Comércio Exterior/ MDIC (BRASIL, 2016) em US\$ FOB, deflacionados para 12/2014 - IPC/USA.

Legenda: BC - Balança Comercial 
Gráfico 3. Evolução do déficit da balança comercial brasileira de medicamentos acabados (em US\$ milhões, FOB)

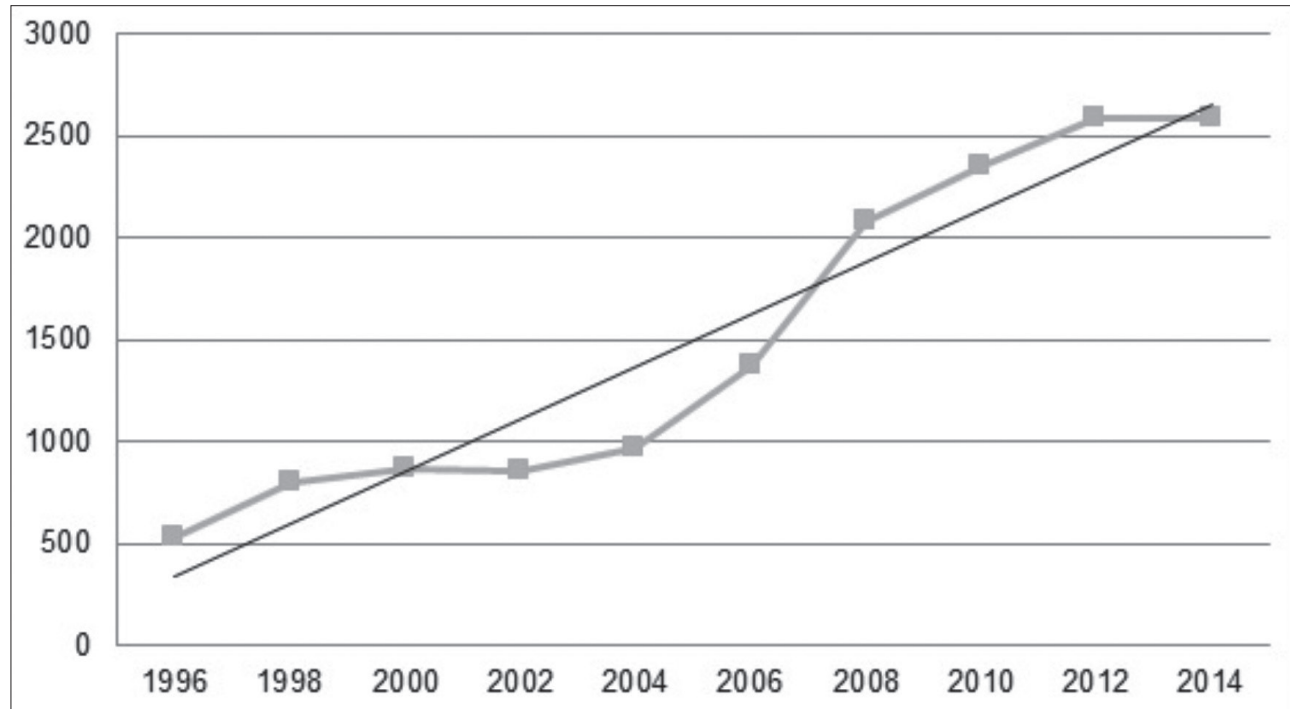

Fonte: elaboração própria, com base em dados do Sistema de Análise das Informações de Comércio Exterior/ MDIC (BRASIL, 2016) em US\$ FOB, deflacionados para 12/2014 - IPC/USA.

Os dados da tabela 3 são bastante eloquentes a respeito da crescente dependência do país de importaçôes de medicamentos acabados, no período estudado. O crescimento do déficit de medicamentos acabados náo prontos para a venda foi de $133,2 \%$, enquanto o de medicamentos acabados prontos para a venda, de $550,9 \%$, mais de quatro vezes maior que o primeiro. É importante destacar que $94,2 \%$ do saldo negativo diz respeito aos medicamentos prontos para a venda, o que contrasta com o crescimento da produção do parque nacional de genéricos, que vem ascendendo a taxas de 25\% ao ano, segundo Renata Gomes et al. (2014, p. 100). Isto sugere que a importaçáo pode estar se concentrando nos medicamentos de maior aporte tecnológico e, consequentemente, maiores preços, o que reforça o quadro de dependência externa. Tal processo corrobora a afirmação de Danielle Giomo e Marina A. Barcelos, para quem a evolução recente da balança comercial brasileira está levando a uma crescente "dependência de importaçóes de produtos de maiores intensidades tecnológicas e a especialização da pauta exportadora em produtos de baixo valor agregado" (2016, p. 9). O estudo da ABDI, já mencionado, destaca que 
$65 \%$ do déficit total na balança comercial no conjunto de segmentos que integram o CEIS correspondiam à importação de medicamentos e de fármacos (2013, p. 21), o que confirma os achados do nosso estudo.

As iniciativas recentes relativas ao setor desenvolvidas no período - engenharia reversa restrita aos antirretrovirais, genéricos e PDPs - apresentam baixa capacidade de transformação dessa tendência de reversão do déficit comercial, uma vez que não alteram a situação relativa aos fármacos nem a tendência à importação de medicamentos acabados. Da mesma forma, estão de acordo com a perspectiva da integração, ou inserção competitiva (SALLUM JR., 2010, 2015). Tais iniciativas, desenvolvidas no âmbito da PNM, restringiram-se a reduzir o custo dos medicamentos comprados no âmbito das políticas de assistência farmacêutica do SUS e não guardam relação com todas as diretrizes daquela política, entre as quais, salientamos: o desenvolvimento científico e tecnológico; promoção da produção de medicamentos e desenvolvimento e capacitação de recursos humanos (BRASIL, 1998). Os resultados da pesquisa relativos ao comércio exterior estáo de acordo, ainda, com a afirmação de diversos autores já mencionados, como Eduardo Pinto e Reinaldo Gonçalves (2016) e Danielle Giomo e Marina Assunção Barcelos (2016), entre outros, no sentido de que as principais consequências da adoção do MLP sobre a IFB foram: aumento das importaçóes, déficit da balança comercial e dependência tecnológica crescentes, resultando em vulnerabilidade sanitária e econômica.

\section{Conclusões}

Os dados da pesquisa indicam que a evolução recente da IFB se deu em conformação com o modelo liberal periférico, hipótese que orientou este estudo. Como se viu, a análise do setor mostrou que houve, em primeiro lugar, um encolhimento de 43,8\% do setor farmoquímico brasileiro, base da indústria farmacêutica; e em segundo, um crescimento muito maior das classes de indústrias ligadas à produção de insumos para o agronegócio - defensivos agrícolas; adubos e fertilizantes; e medicamentos para uso veterinário. Essa evolução confirma, dessa forma, tanto a adequação do setor à tendência à reprimarização das exportaçôes apontada na literatura (PINTO e GONÇALVES, 2016; GIOMO; BARCELOS, 2016), como também vem contribuindo para o aumento da dependência comercial e tecnológica do país quanto às importaçôes de IFA, de produtos farmacêuticos acabados e químicos em geral, 
o que vem sendo assinalado pela literatura recente (BRASIL, 2011; COSTA et al., 2014) e está em total acordo com as características centrais do MLP.

Essa situação encontrada pela pesquisa, particularmente, a insuficiente produção de IFAs, vem agravando a vulnerabilidade sanitária do país, como sugere o recente desabastecimento de medicamentos essenciais-caso recenteda penicilina, queganhou espaço, inclusive, na grande mídia (GLOBO.COM, 22/7/2016; GUIMARÃES, 8/5/2017). Os dados sobre o comércio exterior analisados demonstraram que uma das consequências da evolução da indústria foi o aumento do déficit da balança comercial referente a medicamentos acabados e farmoquímicos. Tal aumento sugere uma crescente dependência do país dos produtos de maior valor agregado e aporte tecnológico, que vem sendo apontada por estudos citados neste artigo (VARGAS, 2010; ABDI, 2013, GOMES, 2014) e também está de acordo com a hipótese da pesquisa. A possível relação entre o aumento da importaçáo de medicamentos de maior valor agregado e aporte tecnológico pode estar por trás do aumento dos gastos com medicamentos pelo setor público (VIEIRA, 2017), relação que precisaria ser investigada por pesquisas futuras.

Não deixa de ser um grande paradoxo que o caminho subordinado tomado pelo Brasil, a partir de 1990, e que vem restringindo o desenvolvimento dos setores de química e de produtos farmacêuticos, entre outros, aconteça num dos maiores mercados de medicamentos do mundo, que conta com um grande sistema público de saúde e que tem, ainda, um dos maiores parques de produção química do mundo (THE EUROPEAN CHEMICAL INDUSTRY COUNCIL, 21/2/2016). Tais condiçôes - dimensôes do mercado, do sistema público de saúde e da indústria química - são bases que permitem uma mudança nos rumos da política para o setor. Ela não ocorre apenas em função da relação de subordinação à qual o país está submetido há quase três décadas. ${ }^{1}$

\section{Referências}

ACHILLADELIS, B.; ANTONAKIS, N. The dynamics of technological innovation: the case of the pharmaceutical industry. Research policy. Brighton, v. 30, n. 4, p. 535-588, Abr, 2001. AGÊNCIA BRASILEIRA DE DESENVOLVIMENTO INDUSTRIAL (ABDI). Logistica reversa para o setor de medicamentos. Brasília: ABDI, 2013. 138 p. 
BASTOS, V. D.; COSTA, L. M. Déficit comercial, exportaçôes e perspectivas da indústria química brasileira. Química. BNDES Setorial. Rio de Janeiro, n. 33, p. 163-206, mar. 2011. Disponível em: <http://www.bndes.gov.br/SiteBNDES/export/sites/default/bndes_pt/Galerias/ Arquivos/c onhecimento/bnset/set3305.pdf>. Acesso em: 12/11/2015.

BERMUDEZ, J. A. Z. Acesso a medicamentos: direito ou utopia? Rio de Janeiro: E-papers, 2014. BRASIL. Câmara dos Deputados. Comissão de Seguridade Social e Família. Relatório Final da Subcomissáo Especial de Desenvolvimento do Complexo Industrial em Saúde, Produção de Fármacos, Equipamentos e outros Insumos. Brasília: Câmara dos Deputados, 2011.

- Casa Civil da Presidência da República/ Ministério do Desenvolvimento, Indústria e Comércio Exterior. Diretrizes para a Política Industrial, Tecnológica e de Comércio Exterior. Brasília: Presidência da República, 2003.

. Ministério da Saúde. Secretaria de Vigilância em Saúde. Departamento de DST, AIDS e Hepatites Virais. Nota Informativa no 006/2016/GAB/DDAHV/MS. Informa a respeito da importância e urgência na aquisição de penicilina cristalina (ou potássica), tendo em vista que tal medicamento é tratamento padrão para diversas doenças com relevante impacto em saúde pública. Disponível em: <http://www.aids.gov.br/sites/default/files/anexos/legislacao/2016/58919/ nota_informativa_no006_importancia_e_urgencia_na_a_82765.pdf $>$. Acesso em: 8/12/2016.

. Ministério de Indústria, Comércio Exterior e Serviços (MDIC). Sistema de Análise das Informações de Comércio Exterior. Disponível em: http://www.aliceweb.mdic.gov.br/; acesso em: 06/11/2016.

. Ministério da Saúde. Portaria GM/MS no. 3.916, de 30 de outubro de 1998. Aprova a Política Nacional de Medicamentos. Brasília: Diário Oficial da União, 10 nov. 1998.

- Conselho Nacional de Secretários de Saúde (CONASS). A Assistência farmacêutica no SUS. Para entender a gestão do SUS. Brasília. (CONASS), 2011.

THE EUROPEAN CHEMICAL INDUSTRY COUNCIL (CEFIC). Facts \& Figures, 2016. Disponível em: <http://www.cefic.org/Facts-and-Figures/>. Acesso em: 21/2/2016.

CANO, W. A desindustrialização no Brasil. Economia e Sociedade. Campinas, v. 21, Número Especial, p. 831-851, dez. 2012.

CARCANHOLO, M. Inserção externa e vulnerabilidade da economia brasileira no governo Lula. In: CONSELHO REGIONAL DE ECONOMIA DO RIO DE JANEIRO; CENTRO DE ESTUDOS PARA O DESENVOLVIMENTO. Os anos Lula: contribuiçóes para um balanço crítico 2003-2010. Rio de Janeiro: Ed. Garamond, 2010, p.109-131.

COSTA, J. C. S. et al. Avaliação do setor produtivo farmoquímico no Brasil: capacitação tecnológica e produtiva. RECIIS - Rev Eletron de Comun Inf Inov Saúde. Rio de Janeiro, v. 8, n. 4, p. 443-460, dez. 2014. 
DÓRIA, R. M. et al. Indicadores secundários do Complexo Industrial da Saúde. In: HASENCLEVER, Lia et al. Desafios de operação e desenvolvimento do Complexo Industrial da Saúde. Rio de Janeiro: E-papers, 2016

FIORI, J. L. História, estratégia e desenvolvimento: para uma geopolítica do capitalismo. São Paulo: Boitempo, 2014.

GADELHA, C. A. G. O complexo industrial da saúde e a necessidade de um enfoque dinâmico na economia da saúde. Ciênc. Saúde Coletiva. Rio de Janeiro; v. 8, n. 2, p. 521-535, jan. 2003.

Desenvolvimento, complexo industrial da saúde e política industrial. Rev. Saúde Pública. São Paulo, v. 40, n. esp., p. 11-23, dez. 2006

(Coord.). Perspectivas do investimento em saúde. Rio de Janeiro: UFRJ, Instituto de Economia, 2008/2009. 217 p. Relatório integrante da pesquisa "Perspectivas do Investimento no Brasil”, em parceria com o Instituto de Economia da UNICAMP, financiada pelo BNDES. Disponível em: <http://www.projetopib.org/?p=documentos>. Acesso em: 10/10/2016.

et al. Saúde e desenvolvimento no Brasil: avanços e desafios. Rev. Saúde Pública. São Paulo, v. 46, p. 13-20, dez. 2012.

GADELHA, C. A. G. et al. The health care economic-industrial complex: Concepts and general characteristics. Health, v. 05, p. 1607-1621, 2013.

GIOMO, D.; BARCELOS, M. A. Comércio internacional e especialização produtiva brasileira. In: 10 ENCONTRO DA NACIONAL DE ECONOMIA INDUSTRIAL E INOVAÇĀO [=Blucher Engineering Proceedings, v. 3 n. 4]. 2016, São Paulo, Anais... São Paulo: Blucher, 2016, p. 283-302. ISSN 2357-7592, DOI 10.5151/engpro-1enei-017.

GIOVANNI, G. A questão dos remédios no Brasil, produção e consumo. São Paulo: Livraria e Editora Polis, 1980.

GLOBO.COM. G1. Falta penicilina no Brasil para tratar crianças que nascem com sífilis. Bom Dia Brasil. 22 jul 2016. Disponível em: <http://g1.globo.com/bom-diabrasil/noticia/2016/07/ falta-penicilina-no-brasil-para-tratar-criancas-que-nascem-comsifilis.html>. Acesso em: $8 / 12 / 2016$.

GOMES, R. et al. O novo cenário de concorrência na indústria farmacêutica brasileira. Complexo Industrial da Saúde. BNDES Setorial. Rio de Janeiro, v. 39, p. 97-134, 2014. Disponível em: <https://web.bndes.gov.br/bib/jspui/handle/1408/4541>. Acesso em: 12/11/2015.

GONÇALVES, R. Desenvolvimento às avessas: verdade, má-fé e ilusão no atual modelo brasileiro de desenvolvimento. Rio de Janeiro: LTC, 2013.

GRACE, C. The Effect of Changing Intellectual Property on Pharmaceutical Industry Prospects in India and China: Considerations for Access to Medicines. Londres: DFID Health Systems Resource Centre, 2004. 
GUIMARÃES, K. Falta de penicilina afeta pacientes no mundo. Folha de São Paulo. 8/5/2017. Disponível em: <http://www1.folha.uol.com.br/equilibrioesaude/2017/05/1881791-falta-depenicilinaafeta-pacientes-no-mundo.shtml>. Acesso em: 10/10/2017.

INSTITUTO BRASILEIRO DE GEOGRAFIA E ESTATÍSTICA (IBGE). Diretoria de Pesquisas. Coordenação de Indústria. Pesquisa Industrial Anual - Empresa. Rio de Janeiro: IBGE, 2004. (Série Relatórios Metodológicos, volume 26).

. Pesquisa de inovação tecnológica: 2008. Rio de Janeiro: IBGE, 2010.

- Comissão Nacional de Classificação - Concla. Classificação Nacional de Atividades Econômicas, versão 1.0. Rio de Janeiro: IBGE, 2004.

. Comissão Nacional de Classificação - Concla. Classificação Nacional de Atividades Econômicas, versão 2.0. Rio de Janeiro: IBGE, 2007.

INSTITUTO DE PESQUISA ECONÔMICA APLICADA (IPEA), IPEADATA. Inflação: IPCA. Disponível em: <http://www.ipeadata.gov.br/Default.aspx>. Acesso em: 27/11/2016.

KORNIS, G. E. M. et al. Os marcos legais das políticas de medicamentos no Brasil contemporâneo (1990-2006). Rev. APS. Juiz de Fora, v. 11, n. 1, p. 85-99, mar. 2008.

LOYOLA, M. A. AIDS e Saúde Pública: a implantação de genéricos no Brasil. In: CORRÊA, M.; CASSIER, M. (Orgs.). AIDS e Saúde Pública: contribuições à reflexão sobre uma nova economia política do medicamento no Brasil. Rio de Janeiro: EdUERJ, 2010, p. 17-70.

MAGALHÂES. L. C. G. et al. Tendências da balança de comércio exterior da indústria farmacêutica brasileira: evolução das importaçóes e exportaçóes de farmoquímicos e medicamentos na década de 1990. Planejamento e Políticas Públicas. Brasília, v. 26, p. 35-63, jun. 2003.

MEINERS, C. M. W. A. Patentes farmacêuticas e saúde pública: desafios à política brasileira de acesso ao tratamento antiretroviral. Cad. Saúde Pública. Rio de Janeiro, v. 24, n. 7, p. 1.4671.478 , jul. 2008.

MITIDIERI, T. L. et al. Há espaços competitivos para a indústria farmoquímica brasileira? Reflexôes e propostas para políticas públicas. Complexo Industrial da Saúde. BNDES Setorial. Rio de Janeiro, v. 41, p. 1-36, 2015.

MOTA, F. B.; CASSIOLATO, J. E.; GADELHA, C.A. G. Articulação da indústria farmacêutica brasileira com o exterior: há evidências de especialização regressiva? Cad. Saúde Pública. Rio de Janeiro, 28(3): 527-536, mar. 2012.

NÚCLEO DE ESTUDOS DE POLÍTICA PÚBLICA (NEPP). Universidade Estadual de Campinas (Unicamp). O Setor Saúde e o Complexo da Saúde no Brasil. Unicamp, Campinas, 2000. (Texto original do sumário executivo da pesquisa).

PALMEIRA FILHO, P. L. et al. O desafio do financiamento à inovação farmacêutica no Brasil: a experiência do BNDES Profarma. Revista do BNDES. Rio de Janeiro, v. 37, p. 67-90, jun. 2012. 
PINTO, A. C.; BARREIRO, E. J. Desafios da Indústria Farmacêutica Brasileira. Quim. Nova. São Paulo, 36(10): 1.557-1.560, 2013.

PINTO, E. C.; GONÇALVES, R. Transformaçôes globais, Modelo Liberal Periférico e Educação no Brasil. Texto para discussão. Rio de Janeiro: Instituto de Economia/ Universidade Federal do Rio de Janeiro, 007, mar. 2016. 23p.

QUEIROZ, S.; CONZÁLES, A. J. V. Mudanças recentes na estrutura produtiva da indústria farmacêutica. In: NEGRI, B.; GIOVANNI, G. Brasil: radiografia da saúde. Campinas: Instituto de Economia/UNICAMP, 2001, p. 123-155.

REZENDE, K. S. Produção: a corda bamba entre o mercado e as necessidades de saúde pública. Uso Racional de Medicamentos: fundamentação em condutas terapêuticas e nos macroprocessos da Assistência Farmacêutica. Série.OPAS/OMS. Brasília, v. 1, n. 4, mar. 2016.

SALLUM JR., B. La especificidad del gobierno de Lula. Hegemonía liberal, desarrollismo y populismo. Nueva Sociedad. Caracas, v. 217, p. 155-171, set. 2008.

É hora da inserção competitiva do País. O Estado de S. Paulo, 22 abril 2010. Disponível em: <http://opiniao.estadao.com.br/noticias/geral,e-hora-da-insercaocompetitivado-pais,541460>. Acesso em: 10/10/2016.

. O impeachment de Fernando Collor: sociologia de uma crise. Sáo Paulo: Editora 34, 2015. $414 \mathrm{p}$.

SAMPATH, P. G. Economic Aspects of Access to Medicines after 2005: Product Patent Protection and Emerging Firm Strategies in the Indian Pharmaceutical Industry. Maastricht: United Nations University-Institute for New Technologies (UNU-INTECH), 2008. Disponível em: $<$ http://www.who.int/intellectualproperty/studies/PadmashreeSampathFinal.pdf $>$. Acesso em: 5/10/2016.

SENADO FEDERAL. Senado Notícias. Desabastecimento de penicilina no SUS será debatido em audiência pública. 12/07/2017. Disponível em: <http://www12.senado.leg.br/noticias/ materias/2017/07/12/desabastecimento-depenicilina-no-sus-sera-debatido-em-audienciapublica>. Acesso em: 10/10/2017.

SENNES, R. O ambiente regulatório, a contribuição das universidades e os desafios do SUS. In: AMARAL, José L. G. (Org.). Seminário Política Nacional de Medicamentos, buscando uma política de medicamentos para o Brasil. São Paulo: Febrafarma, 2008.

SCHWEITZER, S. O. Pharmaceutical economics and policy. Oxford: Oxford University Press, 2007.

TRIAMI MEDIA B. V. e HOME FINANCE. Globalrates. Inflação IPC - Estados Unidos. Disponível em: <http://pt.global-rates.com/estatisticas-economicas/inflacao/indice-deprecosao-consumidor/ipc/estados-unidos.aspx>. Acesso em: 27/11/2016. 
VARGAS, M. A. et al. Reestruturação na indústria farmacêutica mundial e seus impactos na dinâmica produtiva e inovativa do setor farmacêutico brasileiro. In: XV ENCONTRO NACIONAL DE ECONOMIA POLÍTICA. SOCIEDADE BRASILEIRA DE ECONOMIA POLÍTICA (SEP), São Luiz, 2010. Disponível em: <http://www.sep.org.br/artigos/ download?id=1620>. Acesso em: 13/12/2015.

VIEIRA, F. V. Gasto com medicamentos do Ministério e das secretarias de saúde: maiores desafios sob a vigência do congelamento do gasto federal com saúde. In: 3o CONGRESSO BRASILEIRO DE POLÍTICA, PLANEJAMENTO E GESTÃO EM SAÚDE. 2017, Natal. Anais... Natal, 2017, p. 129. Comunicação Coordenada no 13156.

WORLD HEALTH ORGANIZATION (WHO). The World Medicines Situation. Genebra: WHO, 2004. 151 p.

\section{Nota}

${ }^{1}$ C. Kiss participou da análise dos dados, redaçáo do artigo e aprovação da versão final. R. D. F. da Costa e P. H. A. Rodrigues participaram da concepção do estudo, levantamento e análise dos dados, redação do artigo e aprovação da versão final. 


\section{Abstract}

\section{The recent evolution of the Brazilian \\ pharmaceutical industry in the limits of} economic subordination

This study shows the results of the development of the Brazilian Pharmaceutical Industry and trade balance between 1996 and 2014, discussing possibilities of changes in Brazilian industrial policies. The research had two assumptions: industrial possibilities are strongly connected with the international scenario, which has worsened since the 1990s, leaving the country more vulnerable. The data sources were the Annual Industrial Survey of the Brazilian Institute of Geography and Statistics and the Foreign Trade Information System from the Ministry of Industry. The values were adjusted not to consider the inflation. The results show that there was a big imbalance between the performances of the human pharmaceutical products and pharmochemical industries in regards to those focused on the production of chemicals and veterinary pharmaceutical products, in favor of these last ones. The trade balance data show a large and growing trade deficit for medicines for human use. The results corroborated the hypothesis of growing international subordination of the Brazilian pharmaceutical industry and the assumptions mentioned above.

> Keywords: pharmaceutical industry; chemical industry; industrial policies. 